\title{
Optimization of Soxhlet Extraction of Herba Leonuri Using Factorial Design of Experiment
}

\author{
Anees Ahmad (Corresponding author) \\ Environmental Technology Division, School of Industrial Technology \\ Univesriti Sains Malaysia, 11800 Penang, Malaysia
}

Tel: 604-653-2214 E-mail: anees@usm.my, aneesahmad_ana@yahoo.com

\author{
Abbas F. M Alkarkhi \\ Environmental Technology Division, School of Industrial Technology \\ Univesriti Sains Malaysia, 11800 Penang, Malaysia \\ E-mail: abbas@usm.my \\ Sufia Hena \\ Environmental Technology Division, School of Industrial Technology \\ Univesriti Sains Malaysia, 11800 Penang, Malaysia \\ E-mail: sufiahena@yahoo.co.in \\ Bazlul Mobin Siddique \\ Environmental Technology Division, School of Industrial Technology \\ Univesriti Sains Malaysia, 11800 Penang, Malaysia \\ E-mail: bazlu666@yahoo.com \\ Khoo Wai Dur \\ Environmental Technology Division, School of Industrial Technology \\ Univesriti Sains Malaysia, 11800 Penang, Malaysia \\ E-mail: kimmy_yukito@yahoo.co.uk
}

\begin{abstract}
Soxhlet extraction technique is employed for the extraction and separation of chemical constituents in the medicinal plant, Herba Leonuri. The main goal of this analytical study was focused on extracted compounds and extraction conditions themselves. Soxhlet extractions were performed at three extraction time (6h, $9 \mathrm{~h}$ and $12 \mathrm{~h})$ and with two solvents ( $n$-hexane and methanol). A general full factorial design with two factors (extraction time and types of extractor solvents) was implemented. The Soxhlet extraction method presented a good yield of components in extract. The study shows that methanol extracted almost double yield than $n$-hexane. The highest yield obtained with methanol was $14.18 \%$; while the highest yield obtained by $n$-hexane was $7.25 \%$. The results also indicated that, for methanol extraction, the mass yield percent extracted increased with increasing length of extraction period (up to $14.18 \%$ ); for $n$-hexane extraction, the mass yield percent extracted was not consistent with increasing length of extraction period. The extracted oil extracted was analyzed by GC-MS. The compounds identified were vitamin E, palmitic acid and syringol. General characteristics of the Herba leonuri oils obtained by different conditions were further compared, showing that the composition of the Herba leonuri oil extracted by different conditions is mostly similar, whereas relative
\end{abstract}


concentration of the identified compounds is apparently different. This study can be considered as the first information on the chemical compound of Herba leonuri.

Keywords: Soxhlet extraction, Herba leonuri, GC-MS, Factorial design

\section{Introduction}

The development of organic chemistry took place along with the study of plants, mainly in the 19th century, when the first studies on plants were scientifically recorded. This ended up in the isolation of some active plants ingredients, or, medicinal compounds. These active ingredients were obtained, and even today, are employed in the treatment of certain diseases, e.g. morphine, quinine, camphor and cocaine (Wheelwrigh, E.G., 1974; Gottlieb, O.R., 1996).

Nature, in general, has yielded most common organic substances. The plant kingdom contributes, in a more meaningful way, to supply the useful substances for the treatment of human diseases (Phillpson, J.D., 1998). The plant bio-synthesizes special metabolites, which is considered as a defense mechanism for environment, rich in microorganisms, insects, and also to adaptation and regulation conditions (Reinbothe, C., 1990). Thus, plants comprise an enormous laboratory of organic synthesis, as a result of millions of years of evolution and adaptation on Earth.

In the 1900s, the advent of antibiotics produced through microbe fermentation and the remarkable development of synthetic pharmacologicals, soon after World War II, markedly reduced the use of medicinal plants and consequently, the investment in pharmacologicals deriving from plants. In the last decades, a great change in the paradigm of western societies has once again caused plant products to play, an important role in developing countries (Galhiane, M. S., 2006).

Holding an extremely profitable market, the phytopharmacologicals have regained the interest of the pharmaceutical industry in products coming from a vegetal origin. Around 1990, it was estimated that about $80 \%$ of the world population sought, the main source of medicine in the plants (Fleuretin, J., 1990). It is proved that today a great part of the world population, mainly those from developing countries, uses extracted medicines or portions deriving from plants. Herbal medicine is humankind's oldest medicine and also the subject of much current scientific interest. Medicinal plants produce marked therapeutic effects on the human body. They have been used for many years and the interest in medicinal plants is increasing now a day. The majority of them are flowering plants of more than 80 families, including Solanaceae, Aster-aceae, Rosaceae, Leguminosae, Papaveraceae, and Lamiaceae. Some specimens of gymnosperms (Scotch pine, Pinus sylvestris L.), horsetails (Equisetum arvense L.), and algae (sea cabbage, Laminaria jaronica Aresch.) are medicinal plants (Lovkova, M.Ya., 2001).

An advantage of herbal medicinal plants is that they provide a complex of natural compounds to the patients which have smoother action and are better tolerated than synthetic drugs, and produce few allergic reactions. They do not accumulate and therefore can be administered for a long time. Medicinal plants and phytopreparations are used for therapy and prevention of various human diseases, including cardiovascular, gastrointestinal, nervous system, and skin diseases, and even malignancies (Murav'eva, D.A., 1978; Lovkova, M.Ya., 1990; Mashkovskii, M.D., 1988).

Herba leonuri, also named Chinese Motherwort or Siberian Motherwort, belongs to the Labiatae family in the plant kingdom. Native to China, central Europe, Scandinavia and Russia, it is now naturalized in Japan, Java, Malaysia and North America. It is harvested when the stems and leaves are luxuriant before or at the beginning of the flowering season, and dried in the sun or dried after cutting into sections. The dried aerial parts of Herba leonuri (Dan, B., 1993; Zhu, Y. P., 1998) are used in traditional Chinese medicine. Herba leonuri differs from most Chinese herbs and it was often prescribed as a major ingredient when used with other herbal mixtures. Herba leonuri is a major herb, also known as the "mother-benefiting herb". It is indicated in menstruation and child delivery in gynaecology and is especially applicable to conditions of oedema with water retention and blood stasis. In addition, it can also clear toxic substances and subdue swelling due to traumatic injuries, boils and cardiovascular diseases (Dan, B., 1993; Zhu, Y. P., 1998). Herba leonuri was first recorded in Shennong Bencao Jing. The whole plant contains an essential oil, a bitter component (leonurine), an alkaloid (leonurinine), glycosides, and tannins. Herba leonuri has strengthening effects on heart muscle, calms nervous tachycardia and palpitations. Herba leonuri also eliminates gases and intestinal flatulence and used to clean and cure wounds (George D. Pamplona-Roger, 2002).

The essential oil of aromatic herbs is traditionally obtained by hydro distillation, steam distillation, or solvent extraction. These processes are not expensive but can induce thermal degradation, hydrolysis and water solubilization of some fragrance constituents (Guan, W. Q., 2006). Solvent extraction is simpler in terms of the number of steps employed but there are still important choices to be made when designing a process (Jiang, X., 2006).

Solvent extraction of solid sample is commonly known as solid-liquid extraction. In physicochemical terminology, it is referred as leaching or lixiviation and is one of the oldest ways of solid sample pretreatment (Luque de Castro, 1998). Conventionally soxhlet technique was used for the determination of fat in milk (Soxhlet, F., 1879). 
In this study, chemical constituent extraction from Herbs leonuri with Soxhlet extraction process has been studied experimentally. Two extraction conditions including the extraction solvent and length of extraction, on the yield from chemical constituent extraction have been investigated. For extraction solvent, two solvent were studied while for length of extraction, three length of time were studied. The conditions of extraction have been chosen to approximate those most commonly reported in the literature. Compositions of Herba leonuri were analyzed by gas chromatography-mass spectrometry (GC-MS).

The objectives of this study are:

(1) To extract and identify different compounds present in Herba leonuri

(2) To study the effects of parameters (extraction time and solvent type) on the extracted oil of Herba leonuri

(3) To measure the quantity of oil extracted from Herba leonuri

(4) To compare the qualitative of oil extracted using $n$-hexane and methanol

\section{Material and methods}

\subsection{Sampling}

Herba leonuri was purchased from the local market. The samples were ground in grinding mill (Retsh Mill) and sieved to produce samples with particle size of less than $150 \mu \mathrm{m}$. The raw herb powder of particle size less than $150 \mu \mathrm{m}$ was sealed and stored in refrigerator for further usage.

\subsection{Chemicals}

The chemicals used are $n$-hexane (QRëC,purity > 99\%), methanol (Systerm, purity $>99.8 \%$ ), and helium (MOX Gases,Selangor, Malaysia). The solvents used for Gas Chromatography were HPLC grade, solvents used for extraction were analytical grade (purity $>99 \%$ ).

\subsection{Apparatus and Instruments}

The conventional Soxhlet extraction apparatus has been used, consisting of a condenser, a Soxhlet chamber, and an extraction flask. The extractor thimble was Advantec thimble with $22 \mathrm{~mm}$ internal diameter and $90 \mathrm{~mm}$ external length.

\subsection{Soxhlet Extraction and Determination of Percentage Extraction}

The conventional Soxhlet extraction apparatus consisting of a condenser, a Soxhlet chamber, and an extraction flask were used. The time periods for these Soxhlet extraction experiments of 6 hours, 9 hours and 12 hours for the test have been chosen. Three grams of dried and ground Herba leonuri were placed in a Soxhlet apparatus and extracted with 350 $\mathrm{ml}$ of an appropriate solvent for 6 hours, 9 hours and 12 hours. Two solvents were used: (1) n-hexane and (2) methanol. The ratio of Herba leonuri to solvent was about 1:117.

The results are expressed as the yield of crude extract:

$$
Y_{\text {extract }}=100 \times \frac{m_{\text {extract }}}{m_{\text {herb }}}(\%)
$$

where $m_{\text {extract }}$ is the crude extract mass (g) and $m_{\text {herb }}$ is the extracted herb mass (g).

All experiments with Soxhlet were triplicate for statistical evaluation.

\subsection{Sample Analysis (Gas Chromatography-Mass Spectrometry)}

A Hewlett Packard 6890series Gas Chromatography with Autosampler and 5973N Mass Selective Detector and Chemstation Data System was used. Samples were injected into HP-5 crosslinked 5\% phenyl methyl siloxane fused-silica capillary column $(30 \mathrm{~m} \times 0.25 \mathrm{~mm}$ i.d., $\times$ film thickness $0.25 \mu \mathrm{m})$ in the splitless injection mode. The oven temperatures were as follows: the initial temperature was $50^{\circ} \mathrm{C}$, hold $2.5 \mathrm{~min}$. It was raised to $150^{\circ} \mathrm{C}$ at a rate of $15^{\circ} \mathrm{C}$ $/ \mathrm{min}$, then to $200^{\circ} \mathrm{C}$ at the rate of $3^{\circ} \mathrm{C} / \mathrm{min}$ and followed by $8^{\circ} \mathrm{C} / \mathrm{min}$ to $300^{\circ} \mathrm{C}$ and hold for $8 \mathrm{~min}$. Helium, as a carrier gas, was set to a column flow rate of $0.9 \mathrm{~mL} / \mathrm{min}$. Other instrumental parameters were set as: the electron energy was set at $70 \mathrm{eV}$, the ion source temperature set at $230^{\circ} \mathrm{C}$, the quadrupole temperature was $150^{\circ} \mathrm{C}$, the interface temperature was $280^{\circ} \mathrm{C}$ and the injector temperature set at $250^{\circ} \mathrm{C}$, The sample volume was $1 \mu \mathrm{L}$.

A sample of $5 \mathrm{~mL}$ of Herba leonuri extract was evaporated to dryness and reconstituted in $200 \mu \mathrm{L}$ n-hexane or $200 \mu \mathrm{L}$ methanol. The extracts were then subjected to GC-MS analysis. Compounds were identified by matching their mass spectra with those of pure compounds whenever possible. Identification of structures/compounds of the peaks was supported by comparison to commercial mass spectral libraries in NIST (National Institute of Standards and Technologies) and Wiley format. 


\section{Result and discussions}

The results of factorial design with two factors, extraction time (three levels) and two solvents are given in Table 1. Eighteen runs were carried out to cover all possible combination of the two factors.

The results are expressed as the yield of crude extract. It can be seen from Table 1 that the experimental data shows, methanol extraction produced almost double yield than $n$-hexane extraction. The total weight of extract was assumed to be representative of the yield of Herba leonuri oil. Extract obtained by methanol extraction for 12 hours extraction time contained the maximum quantity of extracts thus indicating that the Herba leonuri oil yield would be highest in this case. The n-hexane extract was found to contain the minimum quantity of extracts. At 12 hours extraction time, methanol extraction gave the highest yield which is $14.18 \%$; while $n$-hexane only resulted in $6.87 \%$ mass yield. Methanol extraction obtained the lowest yield at 6 hours extraction time which is only $12.54 \%$. The mass yield trend for methanol extraction is continuously increased, where 6,9 and 12 hours extraction gave $12.54,12.82$ and $14.18 \%$ mass yield respectively. Thus we can conclude that methanol extraction required longer time to obtain high mass yield.

Meanwhile, the highest total amount of yield extracted from Herba leonuri by using $n$-hexane was obtained at 6 hours extraction, which is $7.25 \%$. The mass yield trend for $n$-hexane extraction is not consistent. There was a drop of extent of yield after 6 hours extraction. The lowest quantity of extraction yield was obtained at 9 hours extraction which is only $5.49 \%$. Then, the mass yield increased again to $6.87 \%$ for 12 hours extraction. This n-hexane Soxhlet yields were calculated on dry basis. This result is comparable to the range of $3.37-28.3 \%$ of wet basis obtained with several solvents (Hao, J., 2002).

\subsection{Gas Chromatography - Mass Spectrometry Analysis}

The identification of the target chemical compounds in the herbs samples was carried out by comparison of:

(1) The relative retention times (RRT) obtained when the main(s) characteristic ion(s) of the target compounds were monitored.

(2) The full scan MS spectrum obtained in the sample and the stored ones in the NIST spectral database. Conservative identification criteria were stated for identification of the target compound by the screening method.

Additionally, the mass spectra fit between the suspicious chromatographic peak and the NIST database should be higher than 500 (scaled to 1000) (Careri, M., 2001).

Although the library search is a powerful tool in the identification of unknowns, it can also be a tool given too much credit, especially by inexperienced users. The library search algorithms apply statistical tools to come to their conclusions. The results of this process are easily overemphasized when the best fit from the search is assumed to indicate the identity of the unknown. In such cases, the cast is lost out of sight: the computer with its ability to very rapidly search through a large database and to perform statistical calculations to indicate goodness of fit, the operator with the ability to critically evaluate the search results and to make decisions based on the outcome of the computer search routine. In the evaluation of the search algorithms, an answer is considered to be correct if the retrieved mass spectrum is the correct compound or one of its stereoisomer (Careri, M., 2001).

The library search will possibly only lead to a correct identification if the spectrum of the unknown is actually present in the library and the GC separation has been sufficiently efficient to obtain a sufficiently clean mass spectrum. When the unknown is not present in the library, the search procedure also yields valuable information in pointing out certain structural elements present in the unknowns as well as structural similarities with known compounds. However, this information is only useful in combination with a proper interpretation of the mass spectrum (Careri, M., 2001).

In this study, only three chemical compounds were successfully detected from the extracts which were Vitamin E, Palmitic Acid and Syringol. However, many more compounds eluted from the chromatographic column, although extensive searching of the mass spectral library tentatively identified many more components, with lesser qualities of match. The mass spectrometer software used a standard tuning file, which rates all mass ranges fairly equally when comparing to standard spectra (McDaniel, L. H., 2001).

Vitamin E, Palmitic Acid and Syringol were identified through the database in the GC/MS system and their identities were confirmed through comparison with the standards. Fig.1 presents the chromatogram and the respective spectra of Vitamin E; Fig. 2 presents the chromatogram and the respective spectra of Palmitic Acid; while Fig. 3 presents the chromatogram and the respective spectra of Syringol. These figures show the comparison of the quantity of individual compounds in each extract obtained for each solvent. The major concentration of Vitamin E was achieved in the soxhlet extraction with $n$-hexane. Ge et al. (Ge, Y., 2002) also obtained the similar result where the content of vitamin $\mathrm{E}$ in the extracts obtained by hexane extraction was higher than those extracted with methanol. While the major concentration of palmitic acid was also found in the $n$-hexane extract. Syringol appears in higher amount in the $n$-hexane extract. Vitamin E has two spatially distinct domains: a polar $\mathrm{OH}$ group and a long hydrophobic phytyl side chain. Polar group of Vitamin $\mathrm{E}$ is responsible for its solubility in methanol, whereas its long hydrophobic chain helps to solubilize in $\mathrm{n}$ - 
hexane. Consequently vitamin E can be extracted with any two of the above mentioned solvents whereas syringol and palmitic acid are nonpolar molecules and hence extracted amount was more in case of $n$ - hexane. Soxhlet extraction with $n$-hexane was the better technique to extract vitamin E, palmitic acid and syringol.

\subsection{Design of Experiments}

General factorial design was used to study the effect of two factors, extraction time and type of solvents on extraction of vitamin E, syringol and palmatic acid. Eighteen extractions were required to cover all possible combination. All runs were randomly performed with three replicates.

The results of Analysis of variance (ANOVA) are given in Table 2. It can be seen that hat the effect of both extraction time and type of solvent was significant $(\mathrm{P}<0.0001)$. Furthermore the interaction between time and type of solvent was significant $(\mathrm{P}<0.0001)$. Significant interaction is due to polarity.

This result supports the conclusion that means weights do differ significantly for different treatments. The 12 hours extraction time had the highest yield, whereas 9 hours extraction time had the lowest yield. The average yields for 12 hours extraction time was greater than average for vitamin $\mathrm{E}$, syrigol and palmatic acids.

The plot of the main effect for both factors is give in Fig. 4, showing the behavior of each factor individually.

\section{Conclusions}

Conventional soxhlet extraction has been the most used extraction technique worldwide for a number of decades, surpassing the performance of other extraction alternatives and being used as an efficiency reference for the comparison of its conventional and new counterparts. The study shows that methanol extraction produced higher yield than $n$-hexane extraction, which the extracted yields are almost double. The highest yield obtained with methanol was $14.18 \%$; while the highest yield obtained by n-hexane was $7.25 \%$. The extracted oil was analyzed by GC-MS and the utilization of certified standard allowed the identification of three compounds (vitamin E, palmitic acid and syringol) present in extracts of Herba leonuri. The study shows that both $n$-hexane and methanol extractions can be used to obtain vitamin $\mathrm{E}$ and palmitic acid from Herba leonuri however, methanol was not suitable for extracting syringol. The quantity of syringol extracted with methanol was very low. This study can be considered as the first information on the chemical compound of Herba leonuri. Further, investigations are needed to reflect taxonomic relationships and biochemical activities in Herba leonuri.

\section{References}

Careri, M. and Mangia, A. (2001) Principles and Instrumentation of Gas Chromatography-Mass Spectrometry, in Current Practice of Gas Chromatography-Mass Spectrometry (W.M.A. Niessen, ed.), Marcel Dekker, Inc., 409-440.

Dan, B., Andrew, G. (1993). Herbs that Invigorate the Blood: ChineseHerbal Medicine, Materia Medica, Taos, NM, USA, 267-268.

Fleuretin, J., Pelt, J.-M. (1990). La Recherche 2, 81.

Galhiane, M. S., Rissato, S. R., Chierice, G. O., Almeida, M. V., Silva, L. C. (2006). Influence of Different Extraction Methods on the Yield and Linalool Content of the Extracts of Eugenia uniflora L., Talanta 70, 286-292.

Gammerman, A.F., Kadaev, G.N., and Yatsenko-Khmelevskii, A.A. (1983). Lekarstvennye rasteniya (Medicinal Plants), Moscow: Vysshaya Shkola.

Ge, Y., Ni, Y., Yan, H., Chen, Y. and Cai, T. (2002). Optimization of the Supercritical Fluid Extraction of Natural Vitamin E from Wheat Germ Using Response Surface Methodology. Journal of Fod Science, 67, 239-243.

George D. Pamplona-Roger, M. D. (2002). Encyclopedia of Medicinal Plants, Inter-American Division Publishing Association (IADPA).

Gottlieb, O.R., Kaplan, M.A., Borin, M.R. (1996). Biodiversidade um Enfoque Quimio-biológico, Editora UFRJ, Rio de Janeiro, 267.

Guan, W. Q., Li, S. F., Yan, R. X., Tang, S. K., Quan, C. (2006). Comparison of Essential Oils of Clove Buds Extracted with Supercritical Carbon Dioxide and other Three Traditional Extraction Methods. Food Chemistry, 101,1558-1564.

Hao, J., Han, W., Huang, S., Xue, B., and Deng, X. (2002). Microwave-assisted Extraction of Artemisinin from Artemisia annua L, Seperation Purification Technology, 28,191.

Jiang, X., Ramsay, J. A., Ramsay, B. A. (2006). Acetone extraction of mcl-PHA from Pseudomonas putida KT2440. Journal of Microbiological Methods, 67, 212-219.

Lovkova, M.Ya., Buzuk, G.N., Sokolova, S.M., Kliment'eva, N.I. (2001). Chemical Features of Medicinal Plants (Review) Applied Biochemistry and Microbiology, 37(3), 229-237. 
Lovkova, M.Ya., Rabinovich, A.M., Ponomareva, S.M., Buzuk, G.N., and Sokolova, S.M. (1990). Pochemu rasteniya lechat (Why do Plants Cure), Moscow: Nauka.

Luque de Castro, M.D. and García-Ayoso, L.E. (1998). Soxhlet Extraction of Solid Materials: An Outdated Technique with a Promising Innovative Future. Analytica Chimica Acta, 369,1-10.

Mashkovskii, M.D. (1988). Lekarstvennye sredstva (Medicinal Drugs). Moscow: Meditsina, 1.

McDaniel, L. H., Ashraf-Khorassani, M. and Taylor, L. T. (2001). Supercritical Fluid Extraction of Wood Pulp with Analysis by Capillary Gas Chromatography-Mass Spectrometry. Journal of Supercritical Fluids, 19, $275-286$.

Murav'eva, D.A. (1978). Farmakognoziya (Pharmacognosy). Moscow: Meditsina Niessen, W.M.A. (2001) Principles and Instrumentation of Gas Chromatography-Mass Spectrometry, in Current Practice of Gas Chromatography-Mass Spectrometry (W.M.A. Niessen, ed.), Marcel Dekker, Inc., 1-29.

Phillpson, J.D., Anderson, L.A. (1998). J. Ethnopharmacol., 25, 61.

Reinbothe, C., Diettrich, B., Luckner, M.J. (1990). Plant. Physiol., 137, 224.

Soxhlet, F. (1879), Dinglers' Polyt. J., 232, 461.

Wheelwrigh, E.G. (1974). Medicinal Plants and their History, Dover Publications, New York, NY, pp. 288.

Zhu, Y. P. (1998). Chinese Materia Medica: Chemistry, Pharmacology and Applications, Harwood Academic Publishers, London, 466-468.

Table 1. Mass yield (\%) of extraction of Herba leonuri using two extractor solvents

\begin{tabular}{|c|c|c|c|c|c|c|c|c|}
\hline \multirow{4}{*}{$\begin{array}{l}\text { Extraction Time } \\
\text { (hour) }\end{array}$} & \multicolumn{8}{|c|}{ Mass Yield (\%) } \\
\hline & \multicolumn{4}{|c|}{$n$-hexane } & \multicolumn{4}{|c|}{ methanol } \\
\hline & \multicolumn{3}{|c|}{ Replications } & \multirow{2}{*}{ Average } & \multicolumn{3}{|c|}{ Replications } & \multirow{2}{*}{ Average } \\
\hline & $\mathrm{I}$ & II & III & & $\mathrm{I}$ & II & III & \\
\hline 6 & 7.13 & 7.36 & 7.27 & 7.25 & 12.38 & 12.71 & 12.54 & 12.54 \\
\hline 9 & 5.42 & 5.53 & 5.52 & 5.49 & 12.84 & 12.80 & 12.82 & 12.82 \\
\hline 12 & 6.80 & 6.81 & 7.00 & 6.87 & 14.26 & 14.19 & 14.10 & 14.18 \\
\hline
\end{tabular}

Table 2. Results of analysis of Variance (ANOVA) for mass yield

\begin{tabular}{|l|c|c|c|c|c|}
\hline \multicolumn{1}{|c|}{ Source } & DF & SS & MS & F & P-value \\
\hline Extraction time & 2 & 5.658 & 2.829 & 265.62 & $<0.0001$ \\
\hline Type of solvent & 1 & 198.669 & 198.669 & 18654.36 & $<0.0001$ \\
\hline $\begin{array}{l}\text { Extraction time } * \\
\text { type of solvent }\end{array}$ & 2 & 4.28 & 2.064 & 193.80 & $<0.0001$ \\
\hline Error & 12 & 0.128 & 0.011 & & \\
\hline Total & 17 & 208.582 & & & \\
\hline R-Sq $=99.94 \% \quad \mathrm{R}-\mathrm{Sq}(\mathrm{adj})=99.91 \%$ \\
\hline
\end{tabular}




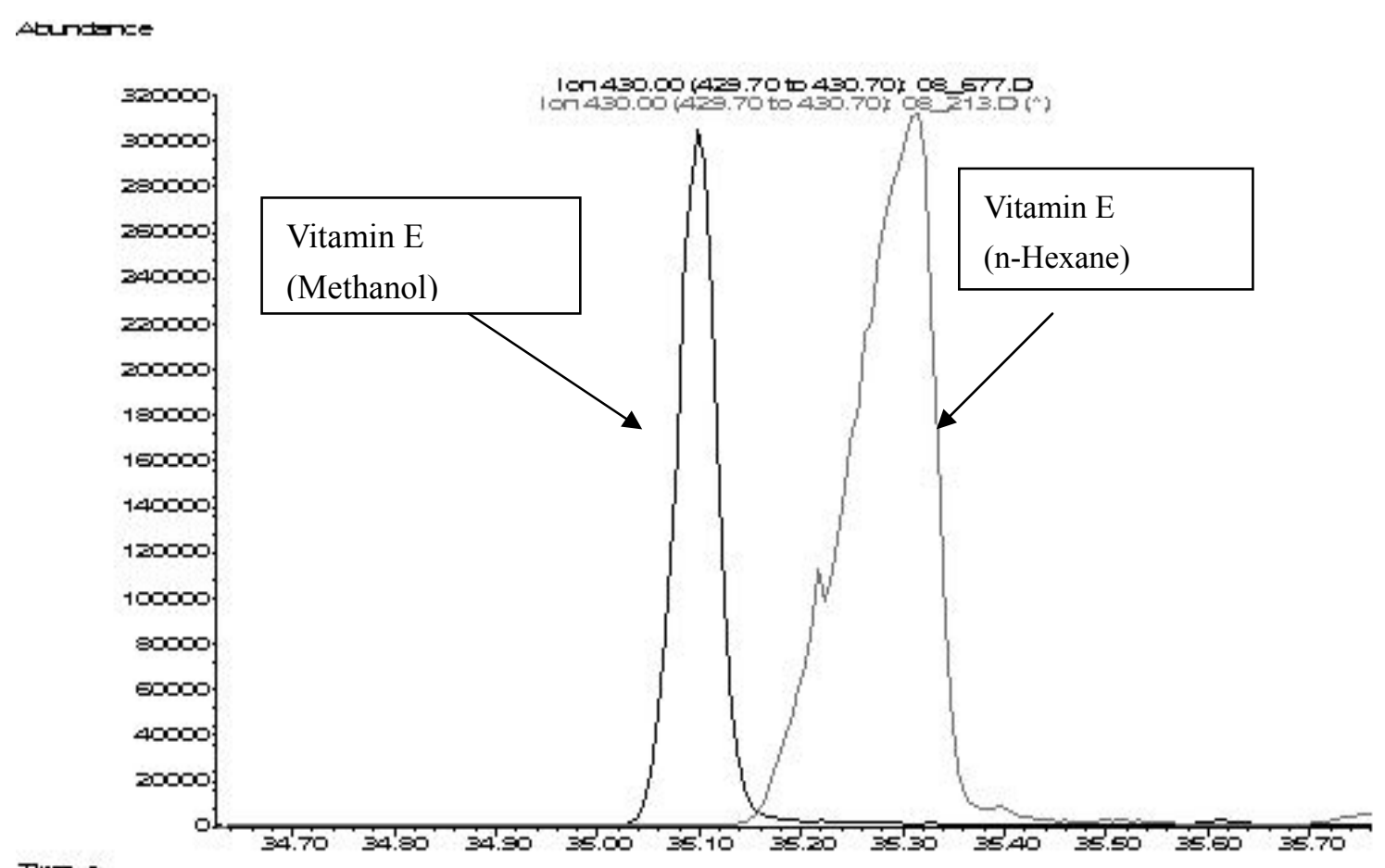

Figure 1. GC-MS Chromatogram and Mass Spectrum of Vitamin E using two extractor solvents

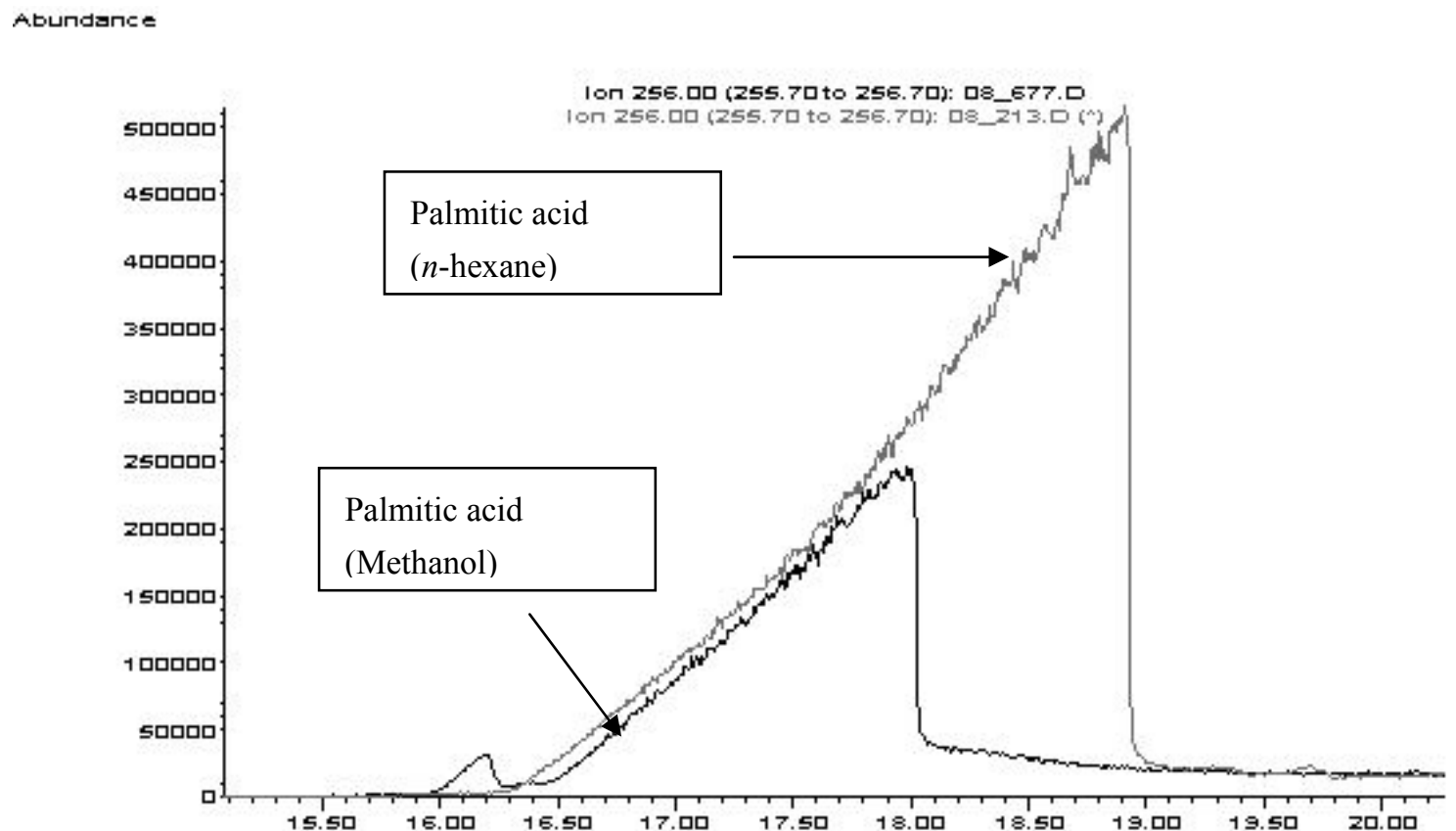

TIre-=

Figure 2. GC-MS Chromatogram and Mass Spectrum of Palmitic Acid using two extracted solvent 


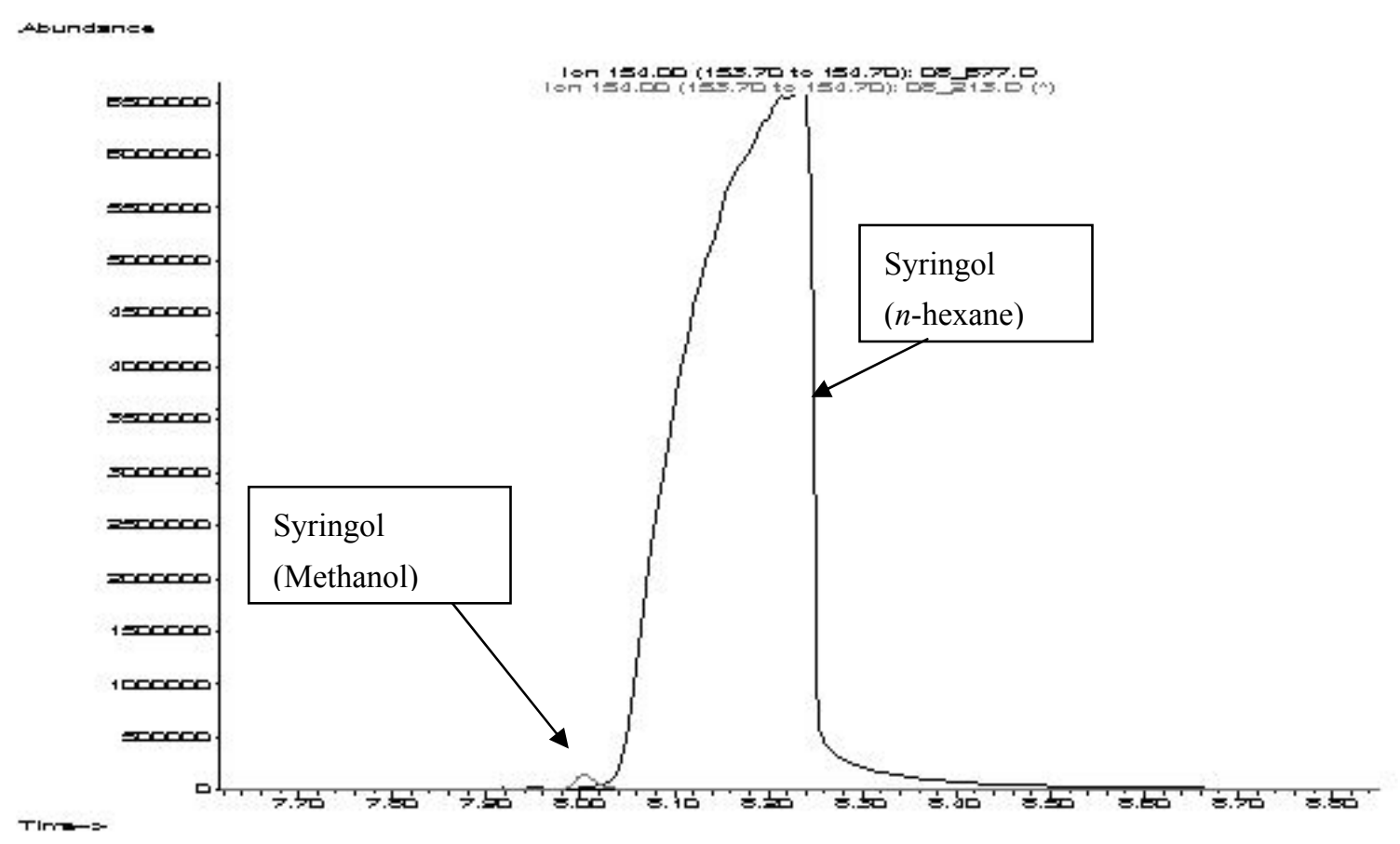

Figure 3. GC-MS Chromatogram and Mass Spectrum of Syringol using two extractor solvents

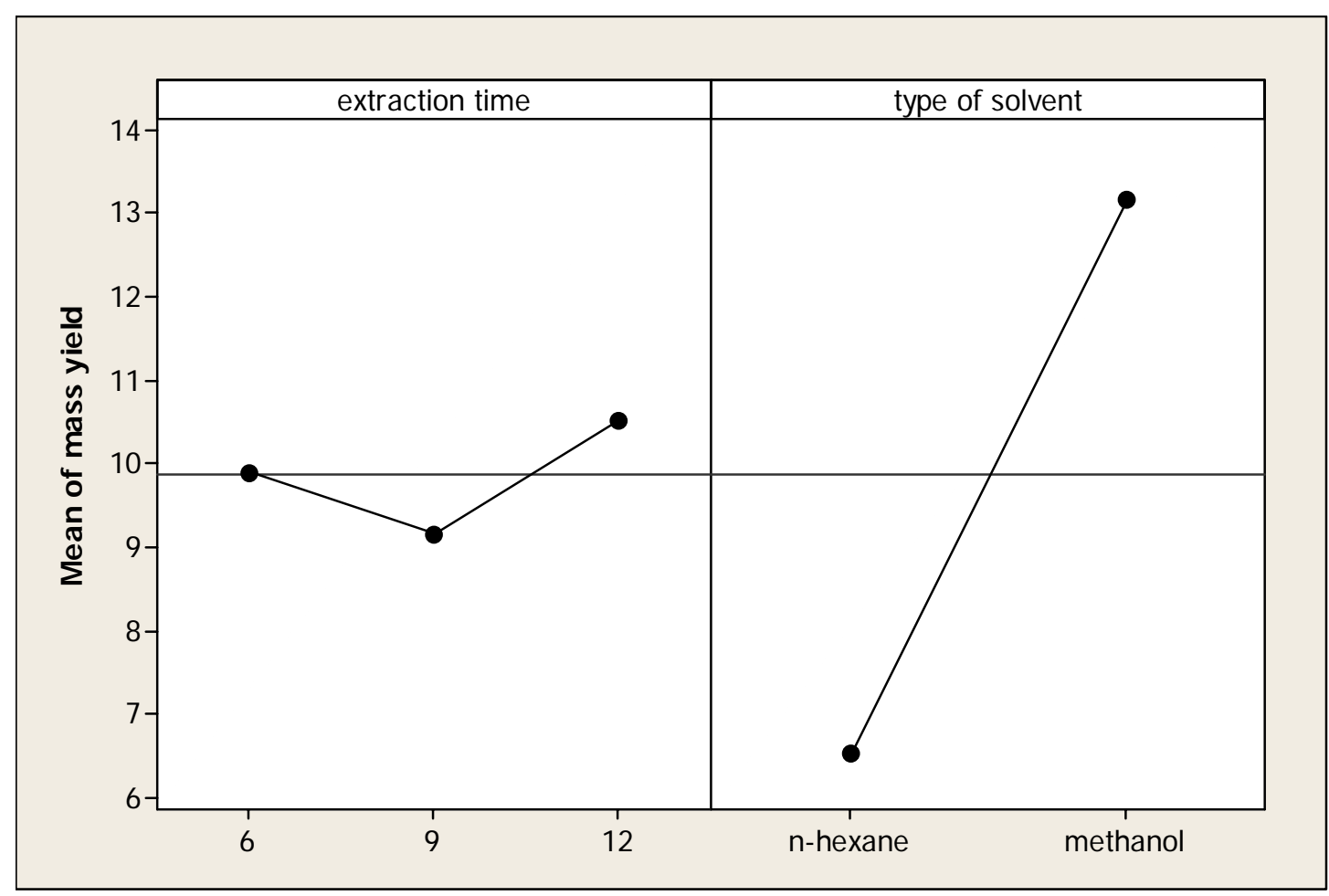

Figure 4. Main Effects Plot (data means) for mass yield 